Article

\title{
Performance and Emission Quality Assessment in a Diesel Engine of Straight Castor and Sunflower Vegetable Oils, in Diesel/Gasoline/Oil Triple Blends
}

\author{
Rafael Estevez ${ }^{1}$, Laura Aguado-Deblas ${ }^{1}$, Alejandro Posadillo ${ }^{2}$, Beatriz Hurtado ${ }^{1}{ }^{\mathbb{D}}$, \\ Felipa M. Bautista ${ }^{1}$, José M. Hidalgo ${ }^{3}{ }^{1}$, Carlos Luna $^{1}{ }^{1}$, Juan Calero ${ }^{1}$, \\ Antonio A. Romero ${ }^{1}$ (D) and Diego Luna ${ }^{1, *(D)}$ \\ 1 Departamento de Química Orgánica, Universidad de Córdoba, Campus de Rabanales, Ed. Marie Curie, \\ 14014 Córdoba, Spain; q72estor@uco.es (R.E.); aguadolaura8@gmail.com (L.A.-D.); \\ b.hurtadocebrian@gmail.com (B.H.); qo1baruf@uco.es (F.M.B.); qo2luduc@uco.es (C.L.); \\ p72camaj@gmail.com (J.C.); qo1rorea@uco.es (A.A.R.) \\ 2 Seneca Green Catalyst S.L., Campus de Rabanales, 14014 Córdoba, Spain; seneca@uco.es \\ 3 Unipetrol Centre for Research and Education, a.s., Unipetrol výzkumne vzdelávací centrum, \\ a.s., Areál Chempark, Záluzí 1, 43670 Litvínov, Czech Republic; jose.hidalgo@unicre.cz \\ * Correspondence: diego.luna@uco.es; Tel.: +34-957212065
}

Received: 21 May 2019; Accepted: 5 June 2019; Published: 7 June 2019

\begin{abstract}
This research evaluates the possibility of using straight oils such as castor oil, which is not suitable for food use, and sunflower oil, used as a standard reference for waste cooking oils, in blends with gasoline as second-generation biofuels. To this end, a study of the rheological properties of biofuels obtained from these double blends has been carried out. The aim is to take advantage of the different properties of gasoline, i.e., its low viscosity and its high energy density to obtain blends whose rheological properties allow the substitution of fossil diesel in high extent. The incorporation of fossil diesel to these gasoline/oil mixtures produces diesel/gasoline/oil triple blends, which exhibited the suitable rheological properties to be able to operate in conventional diesel engines. Therefore, the behavior of these blends has been evaluated in a conventional diesel engine, operating as an electricity generator. The triple blends allow the substitution of fossil diesel up to $40 \%$ with sunflower oil, and up to $25 \%$ with castor oil, with excellent power results achieved for blends in which diesel is substituted up to $40 \%$, and also in fuel consumption at high demand in comparison to conventional fossil diesel. Besides, a significant reduction in the emission of pollutants has also been obtained with these triple blends.
\end{abstract}

Keywords: gasoline oil blends; castor oil; sunflower oil; biofuel; diesel engine; electricity generator; smoke opacity; Bacharach opacity; straight vegetable oils (SVO)

\section{Introduction}

Nowadays, fossil fuels constitute the main source of energy supply for transport. In fact, about 11 billion tons of fossil fuels are consumed each year worldwide [1]. Furthermore, it is expected that the fossil fuel demand will continue to rise, which will unavoidably lead to a scenario where fossil fuels run out [2]. In addition to the depletion of fossil fuels, as the demand for energy continues growing, the undesirable environmental effects linked to its production and consumption are becoming more evident by the day. In fact, emission of smoke, particulate matter (PM), carbon monoxide $(\mathrm{CO})$, carbon dioxide $\left(\mathrm{CO}_{2}\right)$, nitrogen oxides $\left(\mathrm{NO}_{\mathrm{x}}\right)$ and unburnt hydrocarbons (UBHC) from fossil fuel combustion are the primary causes of both atmospheric pollution and human health damage. For this reason, the generation of a safe, efficient and clean energy system is a priority 
objective [3]. Then, there is an urgent necessity for a transition from non-renewable and polluting energies, used up to now by society as a resource to guarantee their energy needs, to other renewable and environmentally sustainable alternatives [4]. However, in order to be competitive and viable, this energy transition model cannot ignore the actual vehicle fleet (more than one billion) operating with fossil fuels [5]. This is the reason why biofuels seem to be the right candidates to start the energetic transition abovementioned. The use of biofuels diminishes the fossil fuels depletion, minimizes the negative impact of Greenhouse Gases (GHG), and also allows using the current car fleet without any mechanic modification of compression-ignition (CI) or diesel engines [6]. In addition, biofuels can be easily integrated into the logistics of the global transport system, through the gradual replacement of fossil fuels by mixtures of diesel/biofuel. In this sense the EU stated that, in 2010, traffic fuels must contain at least $5.75 \%$ renewable bio-components, increasing this percentage up to $20 \%$ in 2020 and $30 \%$ in 2030. These measures foresee to achieve a reduction of $40 \%$ in the Greenhouse Gases emissions in comparison to those in the year 1990, with $27 \%$ of energy consumption from renewable sources and, at least, an increase of $27 \%$ in energy efficiency [7]. Despite these objectives that are apparently not difficult to achieve, replacement of fossil diesel with conventional biodiesel is still considered economically unfeasible, due to different factors associated to the biodiesel purification process, e.g., long reaction times and high energy consumption. Furthermore, during biodiesel production, glycerol is obtained as a by-product, being approximately $10 \mathrm{wt} \%$ of the total biodiesel produced.

To solve this problem, selective transesterification of triglycerides with ethanol has been described to produce monoglycerides (MG) as soluble glycerol derivatives using different lipases as catalysts [8]. Thus, through the partial transesterification of one mole of triglyceride (TG) with ethanol, two moles of ethyl esters (FAEE) and one mole of monoglyceride (MG) are generated, obtaining a biofuel called Ecodiesel that integrates glycerol in the form of a derivative soluble in the FAEE mixtures $[8,9]$. Recent studies stated that the presence of ethanol and other short-chain alcohols has a favorable effect on the emissions of the biofuels [10]. These mixtures improve the volatility of the fuel and constitute the so-called E-diesel, oxidiesel or oxygenated diesel, which in addition to reducing the emissions of the CI engines, improves the flow properties (viscosity) and the essential parameters that limit the application of diesel when operating at low temperatures, such as the "Cloud Point" (CP), "Pour Point" (PP), cold filter plugging point temperature (CFPP), point of occlusion of the cold filter (POFF), and emission levels of the motors without any significant negative effect in most of the parameters that define the quality of biodiesel [11].

In addition, the use of straight vegetable oils (SVO) in double blends with conventional diesel can be also considered as a potential option. All the relevant physicochemical properties of these blends are analogous to conventional diesel, except for the viscosity, which is much higher in oils than in diesel. Since fossil diesel has a much lower viscosity than oils, there will be a maximum percentage for each oil to be mixed with diesel in order to comply with regulations of the EN 14214 standard [12,13]. In this sense, it has been reported that blends with $10-20 \%$ of vegetable oil in diesel can be directly employed in diesel engines without any mechanic modification [14]. Following a strategy similar to that of E-diesel production, the incorporation of alcohols to form triple blends (diesel/biodiesel/alcohol) would further allow increasing the substitution of diesel. However, short-chain alcohols will have difficulty if to be blended with SVO due the different solubility, and also because a phase separation occurs after a short period of time, limiting the use of short-chain alcohols, mainly methanol and ethanol, with vegetable oils in the triple blends abovementioned. In addition, ethanol is corrosive and cannot be easily employed in today's engines or be shipped cheaply through current pipelines [15].

Nevertheless, there is a very interesting exception when castor oil is employed as an SVO due to the special structure of ricinoleic acid, which favors its solubility with alcohols, making possible a higher incorporation of them in triple blends. In fact, a diesel/castor oil/2-propanol triple blend in a proportion of 50/25/25 has been employed in conventional diesel engines, achieving very good results [16,17]. 
Regarding the use of vegetable oils, another strategy consisting the blending of them with less viscous and lower cetane (LVLC) has also been reported [18]. Pine oil (viscosity value of $1.3 \mathrm{cSt}$ ) has been employed in mixtures with castor oil to compensate for the high viscosity of it (226.2 cSt). The properties of castor oil and pine oil are mutually balanced causing a good balance of generated smokes [18], although the low cetane number of pine oil limits its amount in the blends $(30 \%$ by volume) due to engine knocking problems. In addition to pine oil, eucalyptus, camphor and orange oils have been also considered as LVLCs [19]. Likewise, gasoline exhibits viscosity values sufficiently low to obtain important reductions in the viscosity of the oil/gasoline blends. Furthermore, the high energy density of gasoline, only slightly lower than diesel and of course higher than short chain alcohols, as well as its high availability, would allow its use as a blending agent in a more advantageous way than with other renewable compounds already described.

With this in mind, in this study, gasoline has been evaluated, for the first time, as a blending agent to produce a gasoline/oil mixture acting as a LVLC in blends with diesel. This is possible due to the high solubility of any type of vegetable oil with gasoline. The main goal of this research is to achieve a high substitution of fossil fuels, in a feasible way from a technical and economic point of view, and in a short period of time. To do so, two types of oils, which do not compete with food uses and which present high availability, have been chosen. On one hand, sunflower oil has been studied as a standard reference of waste cooking oils and, on the other hand, castor oil has been studied as a reference to oils which are not employed in food uses.

To obtain the optimum gasoline/oil mixture which can be blended with diesel, and maintaining the appropriate parameters of the EN 590 standard, the kinematic viscosity at $40^{\circ} \mathrm{C}$ has been chosen as the most significant parameter, since this is the unique parameter that varies significantly with the proportions of the gasoline/oil blend. The effect of biofuel blends on the performance and emissions of internal combustion engines can be extremely complex to predict, because oils and gasoline show antithetic effects on engine performance in important parameters such as the cetane index (or energy density) and flash point, which promotes positive or negative interactions that are difficult to predict a priori. Furthermore, the cloud and pour point of the blends have been studied.

Once the adequate diesel/gasoline/oil blends were obtained, i.e., met the EN 590 standard parameters, they were tested in a conventional $\mathrm{CI}$ engine, operating as an electricity generator, as it is foreseeable that they exhibit different behaviors. The efficiency obtained is related to the effective electrical power, determined from the voltage and amperage generated by the engine. Furthermore, the contamination degree obtained from the opacity values of the generated smokes has been evaluated, as well as the fuel consumption of the different blends employed.

\section{Materials and Methods}

\subsection{Double Blends of Gasoline/Oil and Triple Blends of Diesel/Gasoline/Oil}

Commercial sunflower oil (food quality), locally obtained, and castor oil (Panreac, Castellar Del Valles, Spain) were blended with gasoline in a first step to obtain the double blends. The double blends which met the requirements of the EN 14214 standard for being employed as biofuels were blended with fossil diesel (from a Repsol service station) in different proportions to obtain the triple blends.

\subsection{Characterization of the Biofuel Mixtures}

The rheological properties that influence most in the correct performance of biofuels are the kinematic viscosity, measured at $40^{\circ} \mathrm{C}$, and cold flow properties. The cold flow properties are determined by several parameters that define its behavior at low temperatures, such as Cloud Point, Pour Point, and point of obstruction of the filter at low temperatures. At low temperatures, the formation of nuclei of solid crystals occurs, increasing in size as the temperatures decrease. The temperature at which the crystals become visible (diameter $\geq 0.5 \mathrm{~mm}$ ) is defined as the Cloud Point, because the crystals typically form a cloudy cloud or suspension. The Cloud Point usually occurs at a temperature higher 
than the Pour Point. Solids and crystals grow quickly and block the passage of fuel lines and filters causing operational problems [20].

\subsubsection{Viscosity Measurements}

The kinematic viscosity has been measured in an Ostwald-Cannon-Fenske capillary viscometer (Proton Routine Viscometer 33200, size 150), determining the time required for a certain volume of liquid to pass between two marked points on the instrument, placed in an upright position. From the flow time $(t)$, expressed in seconds, we obtain the kinematic viscosity expressed in centistokes, $v=C \cdot t$, where $C$ is the calibration constant of the measurement system, specified by the manufacturer $\left(0.040350 \mathrm{~mm}^{2} / \mathrm{s}^{2}\right.$ at $40{ }^{\circ} \mathrm{C}$ ). All measures have been performed in duplicate and are presented as the average of both, with an experimental error less than $0.35 \%$, as required by the standard ASTM (American Society for Testing and Materials) D2270-79 method for calculating the viscosity index from kinematic viscosity at 40 and $100^{\circ} \mathrm{C}$ [16].

\subsubsection{Determination of the Pour Point and Cloud Point of Biofuels}

The Pour Point and Cloud Point are determined by introducing the different double or triple blends, of different composition, in a glass tube having a flat bottom [16]. The tube was tightly closed with the help of a cork carrying a thermometer with a temperature measuring range of -36 to $120^{\circ} \mathrm{C}$. The tube was introduced in a digitally controlled temperature refrigerator for twenty-four hours. The tubes were brought out from time to time and checked until the oil did not show any movement when the jar was horizontally tilted for $5 \mathrm{~s}$. After this time, the loss of transparency of the solution is evaluated. The appearance of turbidity in the samples is indicative that the Cloud Point temperature has been reached (Cloud Point). After a progressive decrease in temperature, the samples are kept under observation until they stop flowing (Pour Point).

2.2.3. Energy Performance and Pollutant Emissions Generated in a Diesel Engine Electric Generator, Fueled with Different Biofuel Blends

Following a previously described experimental methodology [16], the mechanical and environmental characterization of a compression ignition diesel engine has been carried out, working at a rate of $3000 \mathrm{rpm}$ coupled to an AYERBE electric generator, 5KVA, 230v type AY4000MN, for the generation of electricity, operating at a crankshaft constant rotation rate and under different degrees of demand for electrical power. This is achieved by connecting heating plates of 1000 watts each one (Figure 1a). This diesel engine will operate at a constant rate of rotation of the crankshaft and torque, so that the different values of electrical power obtained will be an exact consequence of the mechanical power obtained after the combustion of the corresponding biofuel. Different tests were obtained by providing to the engine double and triple mixtures of different biofuels. The electrical power generated can be easily determined from the product of the potential difference (or voltage) and the electric current intensity (or amperage), see Equation (1), both obtained by means of a voltmeter-ammeter.

$$
\text { Electrical power generated }(\text { Watts })=\text { voltage }(\text { Volts }) \times \text { amperage }(\text { Amps }) \text {. }
$$

The consumption of the diesel engine was calculated estimating the speed of consumption of the biofuel studied with the engine working at a pre-determined demand of electric power. Thus, by operating under the same volume of fuel $(0.5 \mathrm{~L})$, different operation times are achieved. It must be indicated that the values represented are the average of at least three measurements. The error bars are not indicated in Figures for better display, although in none of the cases the error in the measurements exceeded the $5 \%$.

The contamination degree is evaluated from the opacity of the smoke generated in the combustion process. This is obtained by using an opacimeter (TESTO 308, Arquitecsolar, Granada, Spain) under the operating conditions studied, Figure $1 b$ [16]. The data here compiled are the media of three 
repeated measures, attaining an experimental error lower than $6 \%$. The results obtained with the biofuels evaluated were compared with the measurements obtained when conventional diesel was fueled. The opacity value can be expressed as a percentage (being $100 \%$ totally cloudy and $0 \%$ totally clear) or as an equivalent number called the $k$ value (Opacity Bacharach) in a scale which goes from white (0 Bacharach unit) to black (9 Bacharach units), as established by the ASTM D 2156-94, Standard Test Method for Smoke Density in Flue Gases from Burning Distillate Fuels [21].

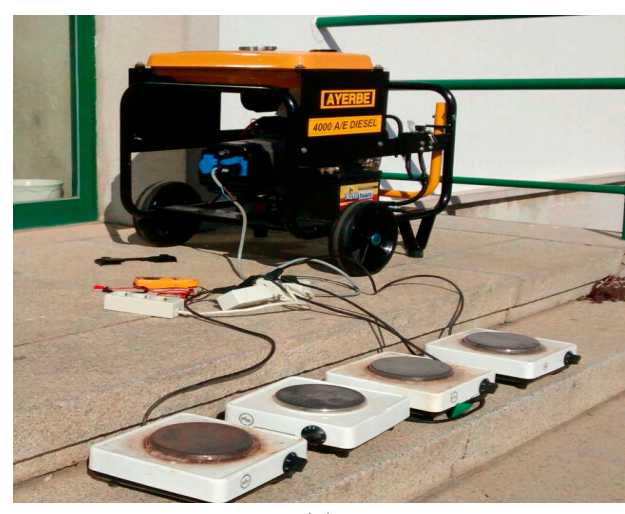

(a)

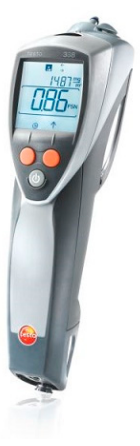

(b)

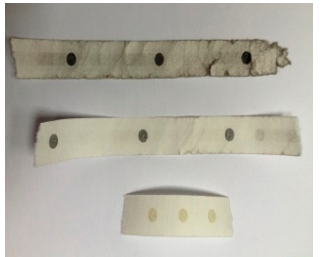

Figure 1. Electrogenerator AYERBE, 5KVA, 230v tipo AY4000MN, heating plates of 1000 watts of power each and voltmeter-ammeter devise (yellow color, on the floor) (a); TESTO 308 opacity meter, which operates as established by the ASTM D 2156-94, Standard Test Method for Smoke Density in Flue Gases from Burning Distillate Fuels (b).

\section{Results and Discussion}

\subsection{Rheological Properties of Gasoline/Oil Double Blends, and Diesel/Gasoline/Oil Triple Blends.}

The major difference between diesel fuel and vegetable oils is the viscosity. In general, vegetable oils exhibit viscosity values in the range of $30-45 \mathrm{~mm}^{2} / \mathrm{s}$ or cSt, although castor oil has a much higher value of $227.0 \mathrm{cSt}$. For its part, fossil diesel exhibits values in the range of $2.5-6$ cSt. The viscosity of the biofuel for being employed in a conventional diesel engine has to be in the range of 2.0 to 4.5 cSt (UNE EN ISO 3104). Therefore, viscosity is the essential parameter to modify in any vegetable oil, by mixing it with gasoline, for being employed in current diesel engines. In this respect, due to the importance of viscosity, its correct determination is critical to evaluate the quality of the biofuel. Thus, the viscosity, Cloud Point and Pour Point values of the different gasoline/oil blends studied are collected in Tables 1 and 2. As can be seen, an increase in the gasoline content in the blends promotes a decrease in their viscosity values, as well as a decrease in the Cloud and Pour Point of the double blends.

Table 1. Viscosity values at $40^{\circ} \mathrm{C}($ ASTM D2270-79), cloud point and pour point of the gasoline/sunflower oil blends. Errors are always calculated as the average of three measurements.

\begin{tabular}{cccc}
\hline Gasoline (\%) & Viscosity $(\mathbf{c S t})$ & Cloud Point $\left({ }^{\circ} \mathbf{C}\right)$ & Pour Point $\left({ }^{\circ} \mathbf{C}\right)$ \\
\hline 0.0 & 37.80 & $-7.0 \pm 0.3$ & $-15.0 \pm 0.6$ \\
10.0 & 20.64 & $-8.0 \pm 0.4$ & $-15.6 \pm 0.6$ \\
15.0 & 17.07 & $-8.6 \pm 0.5$ & $-16.0 \pm 0.6$ \\
20.0 & 13.01 & $-9.1 \pm 0.5$ & $-16.7 \pm 0.7$ \\
25.0 & 9.67 & $-10.0 \pm 0.5$ & $-17.1 \pm 0.6$ \\
30.0 & 7.52 & $-10.5 \pm 0.4$ & $-17.9 \pm 0.7$ \\
35.0 & 5.73 & $-11.2 \pm 0.5$ & $-18.3 \pm 0.7$ \\
40.0 & 4.42 & $-12.0 \pm 0.4$ & $-19.0 \pm 0.7$ \\
45.0 & 3.46 & $-12.8 \pm 0.4$ & $-19.4 \pm 0.8$ \\
50.0 & 2.74 & $-13.6 \pm 0.6$ & $-20.2 \pm 0.8$ \\
100.0 & 1.17 & $-19.0 \pm 0.7$ & $-27.0 \pm 1.1$ \\
\hline
\end{tabular}


Table 2. Viscosity at $40{ }^{\circ} \mathrm{C}$ (ASTM D2270-79), cloud point and pour point values of the gasoline/castor oil blends. Errors are always calculated as the average of three measurements.

\begin{tabular}{cccc}
\hline Gasoline (\%) & Viscosity $(\mathbf{c S t})$ & Cloud Point $\left({ }^{\circ} \mathbf{C}\right)$ & Pour Point $\left({ }^{\circ} \mathbf{C}\right)$ \\
\hline 0.0 & 226.20 & $-4.0 \pm 0.2$ & $-24.0 \pm 1.1$ \\
10.0 & 137.13 & $-7.0 \pm 0.3$ & $-24.2 \pm 1.1$ \\
15.0 & 100.73 & $-7.5 \pm 0.3$ & $-24.3 \pm 1.1$ \\
20.0 & 58.96 & $-8.1 \pm 0.4$ & $-24.7 \pm 1$ \\
25.0 & 45.23 & $-8.9 \pm 0.4$ & $-24.9 \pm 1.2$ \\
30.0 & 36.52 & $-10.3 \pm 0.5$ & $-25.0 \pm 1.2$ \\
35.0 & 28.52 & $-11.0 \pm 0.5$ & $-25.2 \pm 1.1$ \\
40.0 & 24.47 & $-11.8 \pm 0.6$ & $-25.4 \pm 1.1$ \\
45.0 & 19.93 & $-12.2 \pm 0.6$ & $-25.7 \pm 1.1$ \\
50.0 & 10.26 & $-13.0 \pm 0.6$ & $-25.8 \pm 1.2$ \\
55.0 & 7.52 & $-13.7 \pm 0.7$ & $25.9 \pm 1.2$ \\
60.0 & 5.01 & $-14.1 \pm 0.7$ & $-26.0 \pm 1.1$ \\
65.0 & 3.58 & $-14.7 \pm 0.8$ & $-26.1 \pm 1.2$ \\
70.0 & 2.98 & $-15.1 \pm 0.8$ & $-26.2 \pm 1.2$ \\
100.0 & 1.17 & $-19.0 \pm 1$ & $-27.0 \pm 1.2$ \\
\hline
\end{tabular}

When sunflower oil is employed, optimum viscosity values for operating in compression ignition engines are achieved with the addition of $35-45 \%$ gasoline. In the case of castor oil, given its higher viscosity, it is necessary to incorporate a greater amount of gasoline in the blends $(60-70 \%)$ to achieve an adequate viscosity value. Anyway, the gasoline/oil blends, in variable proportions, can be employed as a biofuel, even with oils which exhibit higher viscosity values, as is the case of castor oil. It must be highlighted that the presence of gasoline allows pure castor oil to be used without any chemical treatment, i.e., eliminating the transesterification to convert this oil in biodiesel and, therefore, considerably reducing the cost of the process. Be that as it may, the viscosity measurements indicate that it is possible to obtain biofuels with suitable rheological properties for being employed in diesel engines, complying with the European regulations EN 590, which stablish that viscosity at $40{ }^{\circ} \mathrm{C}$ must be in the range of $2.0-4.5 \mathrm{cSt}$.

Regarding the behavior of the double blends at low temperatures, the gasoline/oil blends began to solidify (Pour Point) at temperatures around $-12{ }^{\circ} \mathrm{C}$ and they were completely frozen (Cloud Point) at $-20^{\circ} \mathrm{C}$. This behavior is very similar to that exhibited by conventional fossil diesel, with temperatures around $-10.0^{\circ} \mathrm{C}$ and $-18.5^{\circ} \mathrm{C}$ for Pour Point and Cloud Point, respectively. However, the standard EN 590 classify the diesel fuel into two groups (with several subclasses) destined for specific climatic environments, depending on the geographical areas where it will be used. Therefore, the values of cloud point and pour point are in a wide range, between +5 and $-34^{\circ} \mathrm{C}$.

As abovementioned, triple blends have been obtained by mixing different proportions of diesel with both a gasoline/sunflower oil blend with $40 \%$ of gasoline (Table 3) and also with a gasoline/castor oil blend with $60 \%$ of gasoline (Table 4). These triple blends are designated with the percentage that represents the corresponding gasoline/oil mixture, considering its biofuel character.

Hence, the B20 triple blend contains $80 \%$ of diesel, whereas the remaining $20 \%$ is a mix of gasoline and oil, in the proportions of the double blend previously studied. Therefore, with sunflower oil, since it is used in a double mixture containing $40 \%$ gasoline, the resulting triple blend corresponding to $80 / 8 / 12$ diesel/gasoline/sunflower oil. In the case of castor oil, as the double mixture selected contains $60 \%$ of gasoline, the resulting triple blend corresponds to the proportion $80 / 12 / 8$, diesel/gasoline/castor oil. The gasoline/oil double blends are represented as B100. 
Table 3. Viscosity values of the triple blends, diesel/gasoline/sunflower oil, obtained by adding different amounts of fossil diesel to a double mixture of gasoline/sunflower oil, containing $40 \%$ gasoline.

\begin{tabular}{ccc}
\hline Nomenclature & Diesel/Gasoline/Sunflower Oil & Viscosity (cSt) \\
\hline B20 & $80 / 8 / 12$ & 3.94 \\
B30 & $70 / 12 / 18$ & 4.06 \\
B40 & $60 / 16 / 24$ & 4.06 \\
B50 & $50 / 20 / 30$ & 4.18 \\
B60 & $40 / 24 / 36$ & 4.29 \\
B70 & $30 / 28 / 42$ & 4.41 \\
B80 & $20 / 32 / 48$ & 4.53 \\
B100 & $0 / 40 / 60$ & 4.42 \\
\hline
\end{tabular}

Table 4. Viscosity values of the triple blends, diesel/gasoline/castor oil, obtained by adding different amounts of fossil diesel to a double mixture of gasoline/castor oil, containing $60 \%$ gasoline.

\begin{tabular}{ccc}
\hline Blends & Diesel/Gasoline/Castor Oil & Viscosity (cSt) \\
\hline B20 & $80 / 12 / 8$ & 4.49 \\
B30 & $70 / 18 / 12$ & 3.82 \\
B40 & $60 / 24 / 16$ & 3.82 \\
B50 & $50 / 30 / 20$ & 3.70 \\
B60 & $40 / 36 / 24$ & 3.70 \\
B70 & $30 / 42 / 28$ & 3.46 \\
B80 & $20 / 48 / 32$ & 3.22 \\
B100 & $0 / 60 / 40$ & 5.01 \\
\hline
\end{tabular}

3.2. Energy Performance and Pollutant Emissions Generated in a Diesel Engine Electric Generator, Fueled with Different Biofuel Blends

As was expected, the triple blends of diesel/gasoline/sunflower oil and diesel/gasoline/castor oil exhibited adequate viscosity values to be employed as biofuels in a conventional diesel engine. Therefore, those blends were tested to ensure whether they present enough energy to guarantee the adequate performance of the engine. Furthermore, for comparative purposes, conventional diesel fuel was also employed as reference in the same conditions.

Thus, Figure 2 shows the power generated (Figure 2a) and the opacity in the smokes (Figure 2b) at different power demanded for the triple blends of diesel/gasoline/sunflower oil. In general, a stabilization of the power generated occurs between 3000 and $4000 \mathrm{~W}$. In all the cases, at the highest value of power demanded $(5000 \mathrm{~W})$, a decrease in the power generated was observed. This generalized behavior could be explained by considering that the engine responds to the energy density of the fuel used, i.e., to the cetane index of the blend. Thus, the engine has a nominal capacity of $5000 \mathrm{~W}$ of electrical power, but this could only be achieved when the cetane number is 100 , that is, when pure cetane is employed as fuel. In fact, if we apply the formula (generated power/power demanded) $\times 100$ for the fossil diesel at the higher power-generated value $(5000 \mathrm{~W})$, we can estimate that its cetane number is around 52. This value is very close to the nominal value of the cetane number for fossil diesel (51), as it is collected in EN 590. Consequently, this could be a useful and simple procedure to calculate the cetane number of a fuel in a very approximate way. 

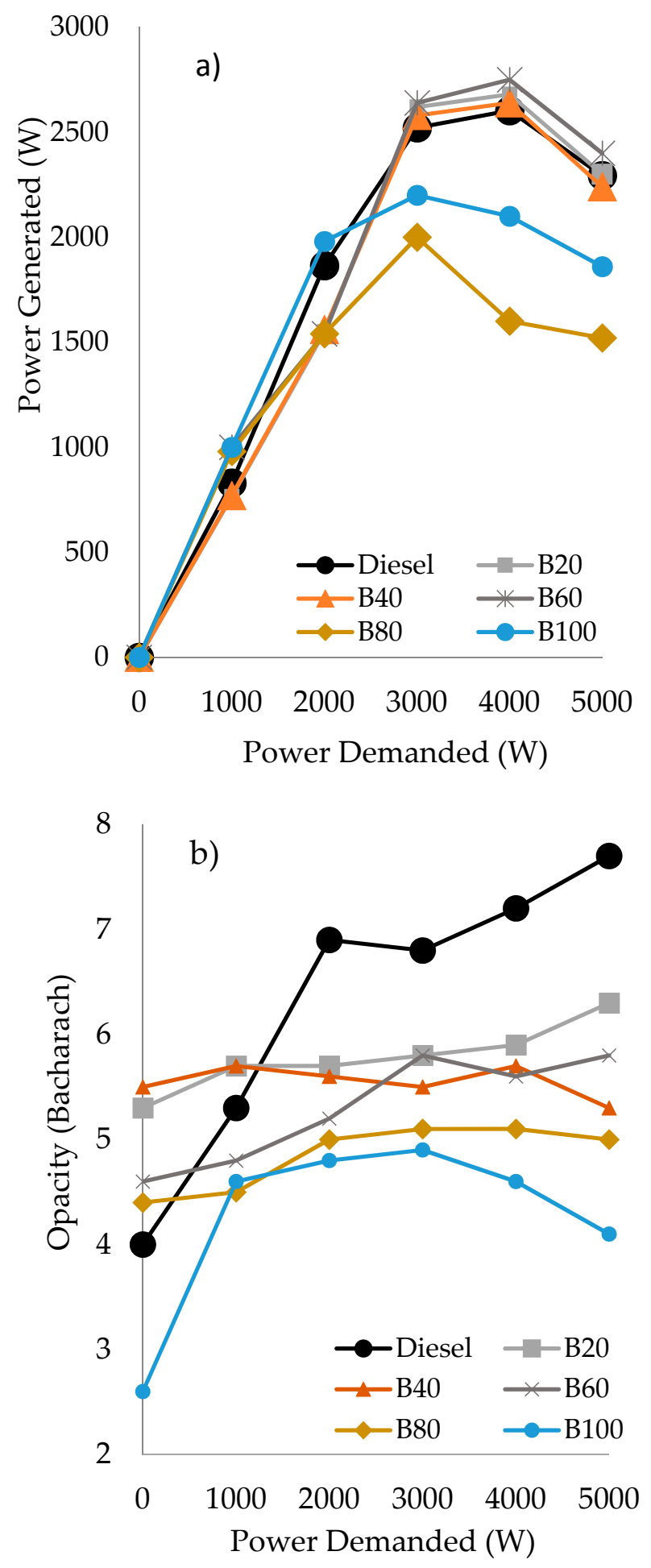

Figure 2. Power generated (in Watts), based on the power demanded (in Watts) (a) and opacity (in Bacharach) as a function of the power demanded (b) by the triple blends of diesel/gasoline/sunflower oil.

Regarding the behavior of the triple blends with sunflower oil (Figure 2a), the B20, B40 and B60 blends exhibited a similar performance than fossil diesel. However, the blends with lower or no amount of diesel in the blend, i.e., B80 and B100, generate lower power values than fossil diesel, which is in agreement with their lower cetane number. Therefore, it seems that, at least, a minimum amount of diesel $(40 \%)$ is required for a good performance of the triple blends. 
According to the contamination results obtained for the blends of diesel/gasoline/sunflower oil (Figure 2b), it can be seen that for all the triple blends, the opacity generated from $2000 \mathrm{~W}$ onwards was lower than with fossil diesel. In fact, the higher the amount of oil, the lower the opacity generated, achieving a considerably reduced opacity with the blend B100. It must be taken into account that all the units have been expressed in units according to ASTM D 2156-94, Standard Test Method for Smoke Density in Flue Gases from Burning Distillate Fuels. The reduction in soot opacities, considerably lower than diesel for the B80 and B100 triple blends, could be partly attributed to the power loss exhibited by them. However, for the blends B20, B40 and B60, these reductions can be mainly attributed to the biofuel chemical properties, as the power generated is similar to fossil diesel.

Considering the blends composed by diesel/gasoline/castor oil, similar results of power generated than those obtained with their counterparts using sunflower oil were obtained for the blends B80 and B100, see Figures 2a and 3a. However, the good results of power generated obtained with B40 and B60, even better than fossil diesel, has to be highlighted, whereas the B20 blend performed in a similar way than diesel. Regarding the opacity generated for the blends with castor oil, see Figure $3 b$, independently on the power demanded from $1000 \mathrm{~W}$ onward, all the blends performed better than fossil diesel. Furthermore, in comparison to the behavior observed with the blends of diesel/gasoline/sunflower oil, their counterparts using castor oil exhibited lower opacity values. Be that as it may, independently of the vegetable oil employed, a significant reduction in opacity values has been obtained, mainly at medium and high demand (from $2000 \mathrm{~W}$ onward), being a reduction in the range of $20-50 \%$ less than that obtained with diesel.

On the other hand, when a biofuel is considered for being employed in a diesel engine, another important factor to be taken into account is the consumption at different power demands. In this sense, the consumption of the different biofuels employed have also been evaluated and the results are plotted in Figure 4.

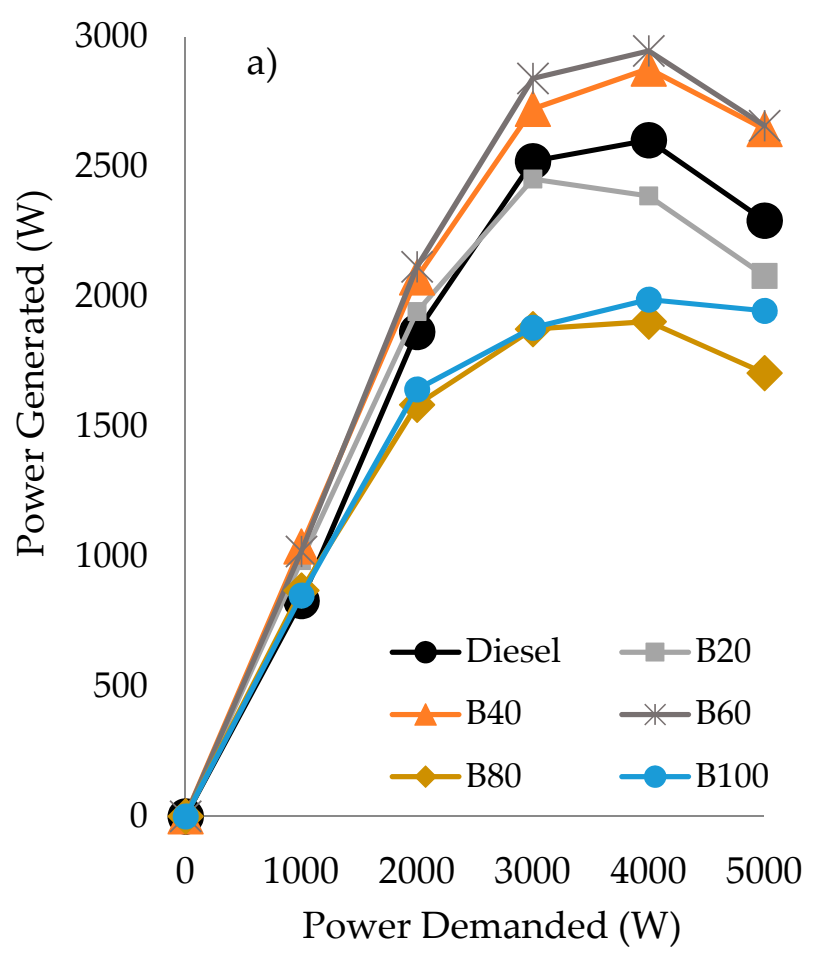

Figure 3. Cont. 


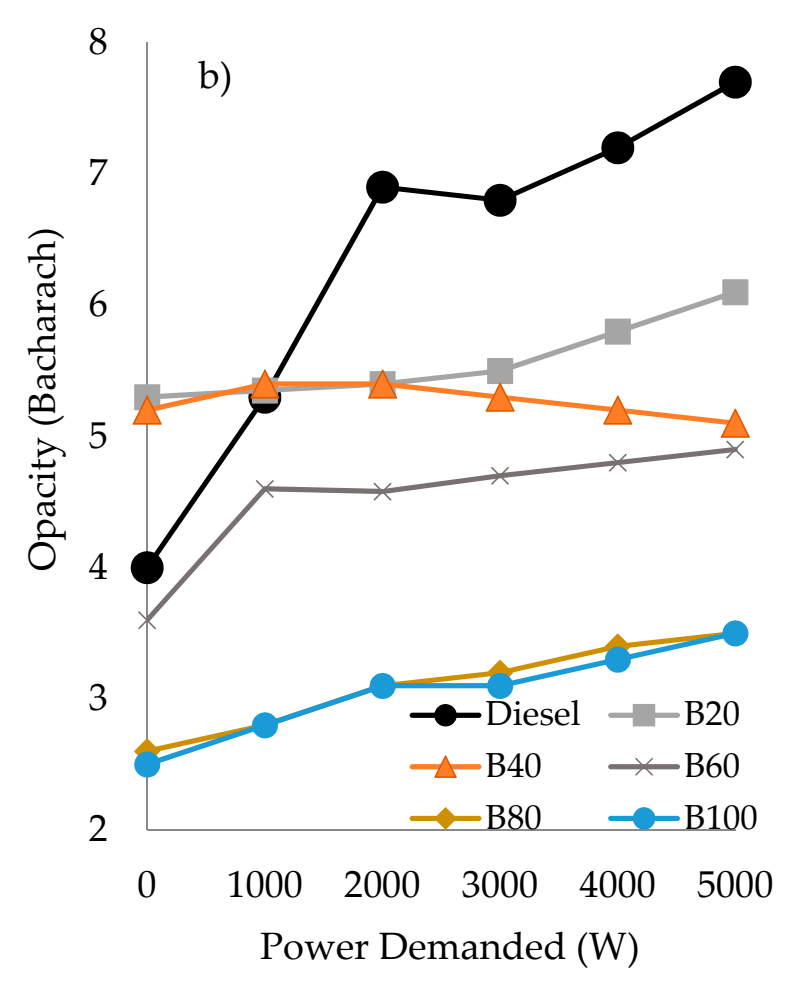

Figure 3. Power generated (in Watts), based on the power demanded (in Watts) (a) and opacity (in Bacharach) as a function of the power demanded (b) by the triple blends of diesel/gasoline/castor oil.

As can be seen, at low power demand $(1000 \mathrm{~W})$, the consumption of the blends is always higher than that obtained with fossil diesel, independently of the oil employed in the blend. However, at the highest power demanded $(5000 \mathrm{~W})$, the opposite behavior is observed. In fact, at $5000 \mathrm{~W}$ of power demanded, only the double blends of gasoline/oil exhibited higher consumption than diesel ( $20 \%$ higher with sunflower and $10 \%$ with castor oil). Anyway, it can be observed that the blends obtained using castor oil exhibited a lower consumption than their counterparts employing sunflower oil.

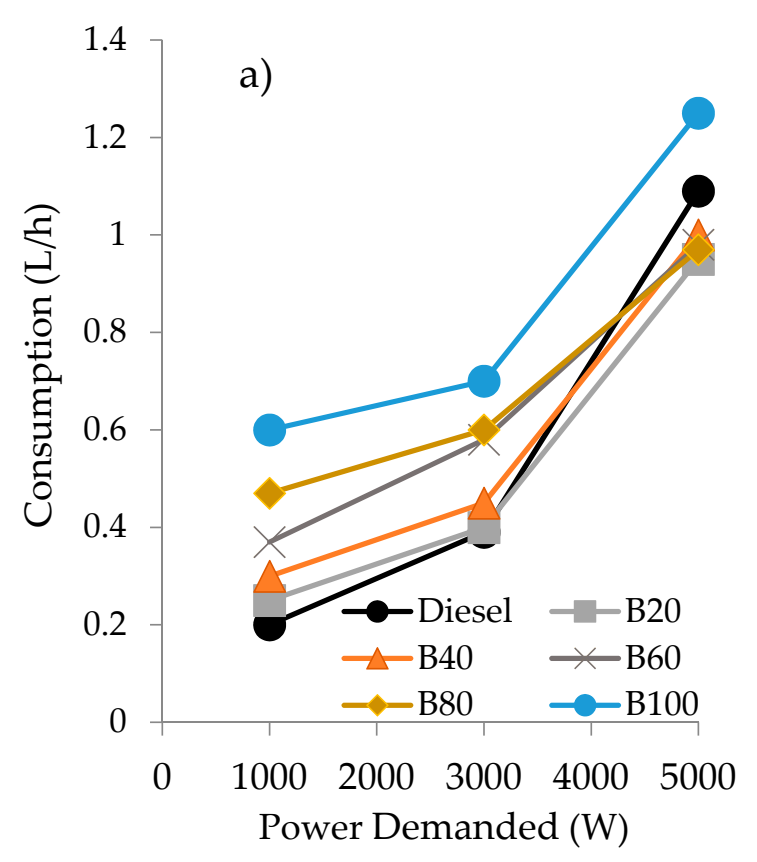

Figure 4. Cont. 


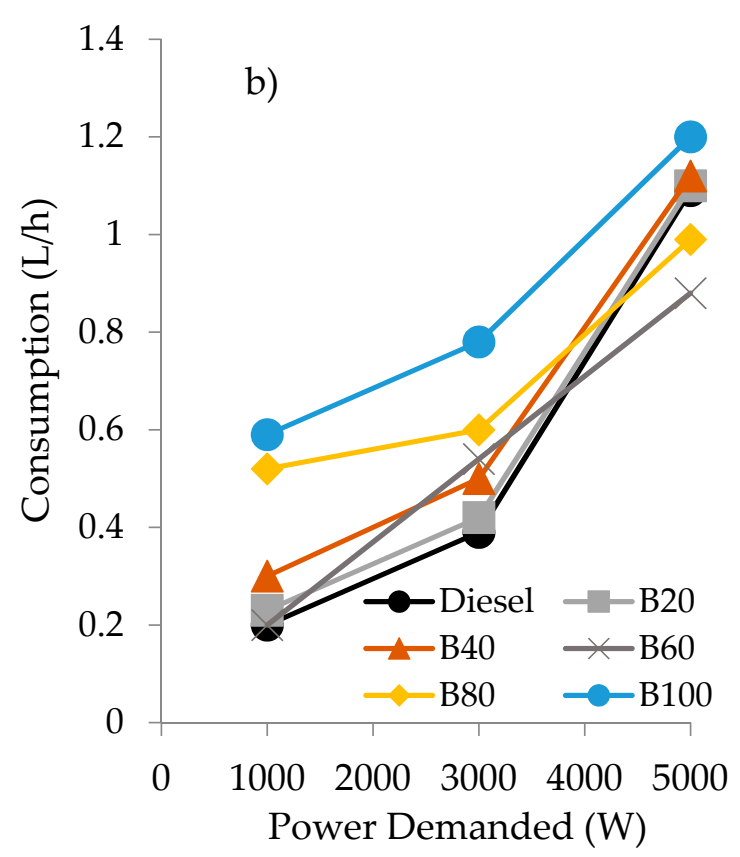

Figure 4. Consumption values as a function of the power demanded of the engine for the blends of diesel/gasoline/sunflower oil (a) and diesel/gasoline/castor oil (b).

\section{Conclusions}

In the present work, an alternative methodology to the chemical transformation of vegetable oil for being employed as biofuels is presented. This methodology consists of a dissolution process of the oil in a suitable solvent, in order to reduce its viscosity to the appropriate level demanded by the EN 590 standard. Specifically, we studied the use of gasoline as a solvent to obtain double blends of gasoline/oil, which are employed as LVLC in blends with fossil diesel. In this sense, two different commercial vegetable oils have been employed, sunflower oil and castor oil. According to the results here reported, the following conclusions have been obtained: The substitution of more than $40 \%$ of fossil diesel can be achieved by the use of triple blends of diesel/gasoline/sunflower oil, whereas $25 \%$ of fossil diesel can be substituted employing their counterparts with castor oil.

- With these blends, promising results of power generation, consumption and opacity of the smokes were obtained in comparison with those obtained with fossil diesel.

- Independently of the oil employed, the B20, B40 and B60 triple blends exhibited the best results in power generated. The lowest values of power generated obtained over B80 and B100 blends can be ascribed to the lower cetane number, as it is relative to the diesel in the blends.

- The opacity obtained with the different blends was always lower than that obtained with fossil diesel from a power demanded from $1000 \mathrm{~W}$ onwards.

- The consumption of the blends studied was higher than that obtained with diesel at lower and medium demand, i.e., 1000 and $3000 \mathrm{~W}$, whereas at the highest demand here studied, $5000 \mathrm{~W}$, the consumption is similar or even better with the diesel/gasoline blends, independently of the oil employed.

In summary, this research show, for the first time, that the substitution of diesel fuel for gasoline allows the incorporation of higher percentages of pure vegetable oils, generating second-generation biofuels capable of operating in current $\mathrm{CI}$ engines without making any mechanical modification in them. In addition, through the use of these triple blends of diesel/gasoline/vegetable oil, the objectives proposed by the EU in the next decades can be achieved, making possible the gradual substitution of fossil fuels by directly using vegetable oils, without performing any type of transesterification 
process. Therefore, this research opens a practical and economically viable alternative to the chemical production of biofuels.

Author Contributions: This research article is part of the doctoral thesis of B.H., directed by professors D.L. and F.M.B., who in a general way conceived and designed the experiments and wrote the paper. C.L., A.A.R., B.H.C. and R.E. made substantive intellectual contributions to this study, making substantial contributions to conception and design of it, as well as to the acquisition, analysis and interpretation of data. Furthermore, D.L. and R.E wrote the paper. All the authors have also been involved in drafting and revising the manuscript, so that everyone has given final approval of the current version to be published in the Energies journal.

Funding: This research received no external funding.

Acknowledgments: This research is supported by the MEIC funds (Project ENE 2016-81013-R), Junta de Andalucía and FEDER (P11-TEP-7723), that cover the costs to publish in open access.

Conflicts of Interest: The authors declare no conflict of interest.

\section{References}

1. Covert, T.; Greenstone, M.; Knittel, C.R. Will we ever stop using fossil fuels? J. Econ. Perspect. 2016, 30, 117-138. [CrossRef]

2. Capellán-Pérez, I.; Mediavilla, M.; de Castro, C.; Carpintero, Ó.; Miguel, L.J. Fossil fuel depletion and socio-economic scenarios: An integrated approach. Energy 2014, 77, 641-666. [CrossRef]

3. Arutyunov, V.S.; Lisichkin, G.V. Energy resources of the 21st century: Problems and forecasts. Can renewable energy sources replace fossil fuels? Russ. Chem. Rev. 2017, 86, 777. [CrossRef]

4. Pang, X.; Mörtberg, U.; Brown, N. Energy models from a strategic environmental assessment perspective in an EU context-What is missing concerning renewables? Renew. Sustain. Energy Rev. 2014, 33, 353-362. [CrossRef]

5. Chu, S.; Majumdar, A. Opportunities and challenges for a sustainable energy future. Nature 2012, 488, 294. [CrossRef] [PubMed]

6. Lopes, M.; Serrano, L.; Ribeiro, I.; Cascão, P.; Pires, N.; Rafael, S.; Tarelho, L.; Monteiro, A.; Nunes, T.; Evtyugina, M. Emissions characterization from EURO 5 diesel/biodiesel passenger car operating under the new European driving cycle. Atmos. Environ. 2014, 84, 339-348. [CrossRef]

7. Dafnomilis, I.; Hoefnagels, R.; Pratama, Y.W.; Schott, D.L.; Lodewijks, G.; Junginger, M. Review of solid and liquid biofuel demand and supply in Northwest Europe towards 2030-A comparison of national and regional projections. Renew. Sustain. Energy Rev. 2017, 78, 31-45. [CrossRef]

8. Calero, J.; Luna, D.; Sancho, E.D.; Luna, C.; Bautista, F.M.; Romero, A.A.; Posadillo, A.; Berbel, J.; Verdugo-Escamilla, C. An overview on glycerol-free processes for the production of renewable liquid biofuels, applicable in diesel engines. Renew. Sustain. Energy Rev. 2015, 42, 1437-1452. [CrossRef]

9. Luna, D.; Calero, J.; Sancho, E.; Luna, C.; Posadillo, A.; Bautista, F.; Romero, A.; Berbel, J.; Verdugo, C. Technological challenges for the production of biodiesel in arid lands. J. Arid Environ. 2014, 102, 127-138. [CrossRef]

10. Sayin, C. Engine performance and exhaust gas emissions of methanol and ethanol-diesel blends. Fuel 2010, 89, 3410-3415. [CrossRef]

11. Aydın, F.; Öğ̈̈t, H. Effects of using ethanol-biodiesel-diesel fuel in single cylinder diesel engine to engine performance and emissions. Renew. Energy 2017, 103, 688-694. [CrossRef]

12. Rakopoulos, D.; Rakopoulos, C.; Giakoumis, E.; Dimaratos, A.; Founti, M. Comparative environmental behavior of bus engine operating on blends of diesel fuel with four straight vegetable oils of Greek origin: Sunflower, cottonseed, corn and olive. Fuel 2011, 90, 3439-3446. [CrossRef]

13. D'Alessandro, B.; Bidini, G.; Zampilli, M.; Laranci, P.; Bartocci, P.; Fantozzi, F. Straight and waste vegetable oil in engines: Review and experimental measurement of emissions, fuel consumption and injector fouling on a turbocharged commercial engine. Fuel 2016, 182, 198-209. [CrossRef]

14. Mat, S.C.; Idroas, M.; Hamid, M.; Zainal, Z. Performance and emissions of straight vegetable oils and its blends as a fuel in diesel engine: A review. Renew. Sustain. Energy Rev. 2018, 82, 808-823. [CrossRef]

15. Savage, N. The ideal biofuel: A biomass-based fuel needs to be cheap and energy dense. Gasoline sets a high standard. Nature 2011, 474, S9. [CrossRef] [PubMed] 
16. Hurtado, B.; Posadillo, A.; Luna, D.; Bautista, F.; Hidalgo, J.; Luna, C.; Calero, J.; Romero, A.; Estevez, R. Synthesis, Performance and Emission Quality Assessment of Ecodiesel from Castor Oil in Diesel/Biofuel/Alcohol Triple Blends in a Diesel Engine. Catalysts 2019, 9, 40. [CrossRef]

17. Kania, D.; Yunus, R.; Omar, R.; Rashid, S.A.; Jan, B.M. A review of biolubricants in drilling fluids: Recent research, performance, and applications. J. Pet. Sci. Eng. 2015, 135, 177-184. [CrossRef]

18. Prakash, T.; Geo, V.E.; Martin, L.J.; Nagalingam, B. Evaluation of pine oil blending to improve the combustion of high viscous (castor oil) biofuel compared to castor oil biodiesel in a CI engine. Heat Mass Transf. 2019, 55, 1491-1501. [CrossRef]

19. Vallinayagam, R.; Vedharaj, S.; Yang, W.; Roberts, W.L.; Dibble, R.W. Feasibility of using less viscous and lower cetane (LVLC) fuels in a diesel engine: A review. Renew. Sustain. Energy Rev. 2015, 51, 1166-1190. [CrossRef]

20. Mohammadi, P.; Tabatabaei, M.; Nikbakht, A.M.; Esmaeili, Z. Improvement of the cold flow characteristics of biodiesel containing dissolved polymer wastes using acetone. Biofuel Res. J. 2014, 1, 26-29. [CrossRef]

21. Blanco, M.; Coello, J.; Maspoch, S.; Puigdomènech, A.; Peralta, X.; González, J.; Torres, J. Correlating Bacharach opacity in fuel oil exhaust. Prediction of the operating parameters that reduce it. Oil Gas Sci. Technol. 2000, 55, 533-541.

(C) 2019 by the authors. Licensee MDPI, Basel, Switzerland. This article is an open access article distributed under the terms and conditions of the Creative Commons Attribution (CC BY) license (http://creativecommons.org/licenses/by/4.0/). 